\title{
Resource Allocation During the COVID-19 Pandemic: Contributions to an Ethical Approach
}

\section{Alocação de Recursos Durante a Pandemia COVID-19: Contributos para uma Abordagem Ética}

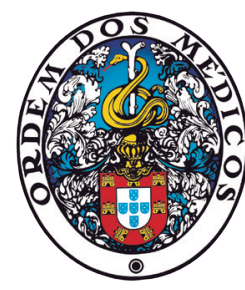

\author{
Margarida SOBRAL $\square^{1}$, Bárbara SANTA-ROSA ${ }^{1,2}$, Margarida SILVESTRE ${ }^{1,3}$ \\ Acta Med Port 2021 Jul-Aug;34(7-8):558-561 - https://doi.org/10.20344/amp.16142
}

\begin{abstract}
The COVID-19 pandemic has brought dramatic worldwide consequences affecting social, economic and healthcare systems. Considering that the number of infected patients requiring admission to intensive care units far exceeded the available resources, healthcare professionals have had to face challenging decisions concerning who should benefit from the limited resources and who should not. In this context, after a careful ethical reflection, we propose some principles to be adopted when dealing with allocation resource decisions, based on core ethical values. Ideally, these strategies should be established and integrated into institutional policies before a crisis scenario, in order to anticipate a potential new public health emergency and prevent possible tragic consequences.

Keywords: COVID-19; Ethics; Pandemics; Resource Allocation; SARS-CoV-2
\end{abstract}

\section{RESUMO}

A pandemia por COVID-19 associa-se a consequências dramáticas a nível social, económico e dos sistemas de saúde. Tendo em conta que o número de pacientes críticos ultrapassa consideravelmente o número de recursos hospitalares disponíveis, os profissionais de saúde depararam-se com decisões difíceis, nomeadamente determinar quais os pacientes que deveriam beneficiar destes recursos escassos. Neste contexto, após uma cuidadosa reflexão ética, propomos alguns princípios a considerar aquando das decisões de alocação de recursos em saúde, baseados em valores éticos fundamentais. Idealmente, estas decisões devem ser estabelecidas e integradas nas políticas institucionais antes de um cenário de crise, de forma a antecipar uma potencial nova emergência de saúde pública e mitigar possíveis consequências trágicas com ela relacionadas.

Palavras-chave: Alocação de Recursos; COVID-19; Ética; Pandemia; SARS-CoV-2

\section{INTRODUCTION}

The pandemic caused by SARS-CoV-2 is unprecedented in recent human history. It has spread so fast worldwide that the impact on economics, social behaviour and healthcare provision has been dramatic.

This health crisis has confirmed that known ethical issues related with the management of infectious diseases remain, despite considerable efforts to recognize and mitigate them in previous outbreaks. ${ }^{1}$

A large-scale study from China indicates that approximately $80 \%$ of the population that is infected will show mild or no symptoms. Of the infected patients, $15 \%$ will have severe symptoms, requiring hospitalization and $5 \%$ will present critical illness, due to an interstitial pneumonia that can exacerbate rapidly into acute hypoxemic respiratory failure and acute respiratory distress syndrome, ${ }^{2}$ therefore requiring admission in Intensive Care units (ICU) and ventilatory support that may be needed for weeks. ${ }^{3-5}$

In several countries, the influx of infected patients presenting life-threatening disease was disproportional to the available resources, which resulted in healthcare professionals having to make difficult decisions, such as choosing who is provided ventilatory support and who is not.

Decision-making processes based on equipment availability, rather than centred on the best interests of specific patients is an unprecedented scenario for many, particularly in developed countries, and has significant ethical implications. $^{2}$

In this paper we propose some principles to be adopted when dealing with allocation resource decisions, based on the core ethical values of justice and beneficence.

\section{Equity and fairness}

The first specific COVID-19 resource allocation strategy was developed in Italy, the earliest European country where the number of infected patients far exceeded available resources, by the Italian College of Anesthesia, Analgesia, Resuscitation, and Intensive Care (SIAARTI). ${ }^{6,7}$

Although not only based on the chronological age of patients, it advocated an age cut-off for ICU admission, if eventually needed. SIAARTI argued that resources should be given to those who have a higher probability of survival and life expectancy, in order to maximize the benefits for the largest number of patients, according to the utilitarian theory of justice. ${ }^{5}$

This approach has been criticized and considered 'ageist', as it disseminates the erroneous idea that age and frailty are equivalent. In fact, ageing is a heterogeneous process and does not always correlate with multimorbidity.

1. Institute of Bioethics. Faculty of Medicine. University of Coimbra. Coimbra. Portugal.

2. National Institute of Legal Medicine and Forensic Sciences, North branch. Porto. Portugal.

3. Reproductive Medicine Department. Coimbra Hospital and University Centre. Coimbra. Portugal.

$\triangle$ Autor correspondente: Margarida Sobral. margarida.sobral4@gmail.com

Recebido: 08 de março de 2021 - Aceite: 27 de abril de 2021 - First published: 19 de maio de 2021 - Online issue published: 01 de julho de 2021 Copyright ( O Ordem dos Médicos 2021 
So, although ageing it is risk factor for mortality, other factors including functional trajectory, multimorbidity and frailty are more predictive..$^{8,9}$

Categorical exclusions based on age and prioritizing automatically younger patients over older ones, disproportionally disfavours older adults and perpetuates injustice by stereotyping the elderly, leading to persistent beliefs that their lives are less valuable or expendable..$^{7,8,10,11}$

If we aim to fight this ageistic approach, then more robust criteria than chronological age, but equally easy-touse in rapid critical decision-making, should be proposed. It should be a parameter that has an impact on prognosis, such as frailty.

There are several procedures that can be used to access frailty. In this context, it is important to use a validated method that is objective, structured, reproducible and evidence-based. We suggest using the Sequential Organ Failure Assessment (SOFA) score; it does not incorporate the patients' age and it is objective, since it relies on the measurement of the vital signs and laboratory test values, allowing the evaluation of the general respiratory, cardiovascular, hepatic, coagulation, renal and neurological systems' function. ${ }^{9,12}$

While waiting for the laboratory values, clinicians can assess frailty using the 9-point Clinical Frailty Scale (CFS). Based on a careful clinical history, focusing on items such as mobility and autonomy for Activities of Daily Living (ADLs) two weeks before the onset of symptoms, they estimate the patient's level of frailty or robustness. The goal is to determine the person's baseline health status and predict adverse health outcomes in a variety of settings, including acute care. ${ }^{13}$

Even though using frailty as a decision marker for ICU care will most likely continue to prioritize access to intensive care towards younger patients, it does not reduce this choice to a parameter that can be as heterogeneous as chronological age. Instead, it sees all patients as equals regardless of the age and prioritizes those who have a possible better outcome.

Moreover, and to guarantee equity and fairness, these criteria should be applied to every patient requiring intensive care, regardless of the diagnosis.

\section{Promoting instrumental value}

Individuals who can save a large number of human lives, such as healthcare professionals and first responders, should be given higher priority. ${ }^{14,15}$ This does not mean that their lives are more worthy or valuable than other individuals, but they have instrumental value, that allows benefits to be maximized, by saving other lives. ${ }^{14}$ If healthcare workers are incapacitated, all patients (not only those with COVID-19), will suffer greater mortality. ${ }^{3}$

Furthermore, it must be considered that intensive care therapies are heavily dependent on trained staff, that cannot easily be replaced. In this scenario, the utilitarian argument is that a pandemic is an extraordinary situation which allows the pursuit of the biggest common benefit. ${ }^{15}$
Beauchamp and Childress argue that it is legitimate to give treatment priority to certain individuals if their contribution is fundamental to achieving a major social goal, based on social utility. However, when using social utility as criteria, we should limit our judgments to the specific characteristics and skills that are essential to the public's immediate protection, without considering the general social worth of people. ${ }^{10}$ Priority given to critical workers must not be misused by prioritizing wealthy or famous persons. ${ }^{3}$

\section{Maximizing benefits}

According to the principle of beneficence, there are no noteworthy ethical differences between withholding and withdrawing life-sustaining treatments if they are considered futile, no longer clinically indicated, or against the patients' best interests. It is, in fact, the medically appropriate decision, regardless of resource scarcity, in cases when the interventions are deemed futile. ${ }^{15-18}$

Moreover, in this pandemic scenario, considering the goal of maximizing population outcomes, it is not sustainable that patients unlikely to survive use scarce resources, such as ventilators, indefinitely..$^{14}$

Therefore, we believe that every ICU admission should be considered an 'ICU trial', as suggested by the SIAARTI's guidelines. This trial period will allow reducing uncertainty about outcomes, by periodically re-evaluating the appropriateness of treatments, patient's clinical course, expected goals and proportionality of ICU care.5,10 The duration of these trials should be defined as early as possible and according to the available data about the natural history of the disease but it can always be subject to changes if subsequent emerging data suggests that the trial duration should be shortened or prolonged. ${ }^{19}$

Reallocation decisions are ethically justifiable, if the chance of benefit from continuous use is low. ${ }^{20}$ However, as they are exceptionally challenging and emotionally demanding, the physicians responsible for direct patient care should not be accountable for these decisions. ${ }^{21}$

Therefore, we suggested the creation of triage committees. This team should include an expert in intensive care medicine, an expert in palliative care, and should be supported by an ethicist. Ethicists should be in charge of supervising the triage process, conducting periodic reassessments of the patients receiving critical care and assigning a level of priority for each one of them. Depending on the patients' response to treatment, and by following ethical principles, this team is responsible for making reallocation decisions, if needed. ${ }^{19}$

An early introduction of palliative care is of paramount importance at this point. For those patients who are severely ill but non-eligible for high-intensity invasive treatments, or those unlikely to benefit from critical care despite maximal intensive care support, optimal, compassionate and respectful palliative care should be provided. $5,7,21$

Psychological and spiritual support must be granted to all patients, their relatives and to healthcare workers, as they have to make hard decisions that lead to moral and 
emotional distress. ${ }^{22,23}$

\section{Transparency in allocation decisions}

Allocation decisions must follow the best ethical standards, be inclusive, reasonable and evidence-based. ${ }^{23}$ Therefore, they should be periodically reviewed and modified according to the new scientific findings, as the pandemic progresses. ${ }^{15}$ Ideally, resource allocation strategies should be established and integrated into institutional policies when an organization is not in crisis. ${ }^{7}$

All changes to ICU admission policies should be communicated to patients and/or their families, explaining the exceptional nature of these measures, to appropriately set expectations, as a matter of duty of transparency and to preserve trust in the health service..$^{11,14}$

\section{CONCLUSION}

The pandemic caused by SARS-CoV-2 is unprecedented in recent human history. Hospitals were overwhelmed with the increasing influx of patients and, in many cases, healthcare professionals had to make difficult decisions on whose life to save, based on resource availability.

The prioritization of patients is inevitable in these circumstances. The aim is to do it properly, and an adequate implementation of medical ethics assumes high importance.

Following the aforementioned discussion, we propose some principles to be adopted when dealing with resource allocation decisions, as synthesized in Fig. 1.

Indeed, there are certain values that cannot be neglected, even in this extraordinary scenario, including consider- ing all human lives as having the same value, respecting patient's autonomy, avoiding harm, and not excluding patients based on their social worth, wealth, cognitive capacities or other non-medically relevant criteria. Moreover, and in order to ensure equity and fairness, these criteria should be applied to every patient requiring intensive care, regardless the diagnosis.

The time constraints in developing allocation frameworks have not permitted a fully participatory approach. However, it is essential that from now on, all those concerned (healthcare professionals, citizens and other experts) in these decisions, have an active voice in the decision-making process.

Ideally, these strategies should be the result of intense and active ethical reflections that are public and should be established and integrated into institutional policies before a crisis scenario, so as to anticipate a potential new emergency in the near or more distant future.

\section{AUTHORS CONTRIBUTION}

MS: Literature research, drafting the word, contribution to the concept and design of the guidelines.

BSR: Supplied literature. Contributed to the draft and critical review of the paper. Contributed to the concept and design of the guidelines. Approved the final version of the manuscript.

MS: Suggested the topic. Supplied literature. Contributed to the draft of successive corrected versions until the final version of the manuscript.

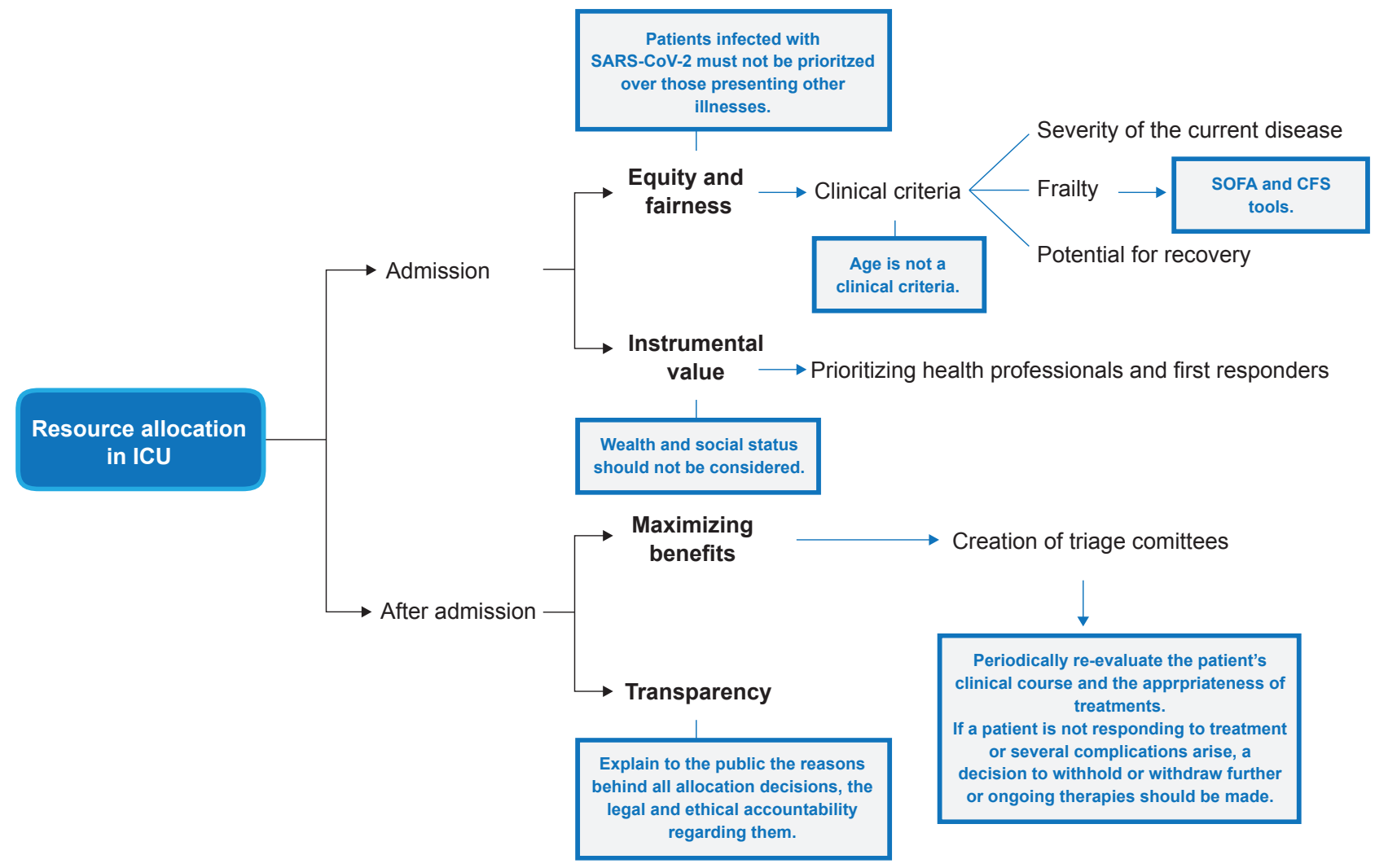

Figure 1 - Recommendations regarding resource allocation 


\section{COMPETING INTERESTS}

The authors declare that they have no conflict of interest with regard to this article.

\section{REFERENCES}

1. Smith MJ, Silva DS. Ethics for pandemics beyond influenza: Ebola, drug-resistant tuberculosis, and anticipating future ethical challenges in pandemic preparedness and response. Monash Bioeth Rev. 2015;33:130-47.

2. Laffey J, Chikhani M, Bates D, Hardman J. Supporting more than one patient with a single mechanical ventilator: useful last resort or unjustifiable risk? Br J Anaesth. 2020;125:247-50.

3. Emanuel E, Persad G, Upshur R, Thome B, Parker M, Glickman A, et al. Fair allocation of scarce medical resources in the time of Covid-19. N Engl J Med. 2020;382:2049-55.

4. Yang $X, Y u$ Y, Xu J, Shu $H$, Xia J, Liu H, et al. Clinical course and outcomes of critically ill patients with SARS-CoV-2 pneumonia in Wuhan, China: a single-centered, retrospective, observational study. Lancet Respir Med. 2020;8:475-81.

5. Dunham A, Rieder T, Humbyrd C. A bioethical perspective for navigating moral dilemmas amidst the COVID-19 pandemic. J Am Acad Orthop Surg. 2020;28:471-6.

6. Boreskie K, Boreskie P, Melady D. Age is just a number - and so is frailty: strategies to inform resource allocation during the COVID-19 pandemic. CJEM. 2020;22:411-3.

7. Farrell T, Ferrante L, Brown T, Francis L, Widera E, Rhodes R, et al AGS position statement: resource allocation strategies and age-related considerations in the COVID-19 era and beyond. J Am Geriatr Soc. 2020;68:1136-42.

8. Farrell T, Francis L, Brown T, Ferrante LE, Widera E, Rhodes R, et al. Rationing limited healthcare resources in the COVID-19 era and beyond: ethical considerations regarding older adults. J Am Geriatr Soc. 2020:68:1143-9

9. Rosen T, Ferrante L, Liu S, Benton E, Mulcare M, Stern M, et al. Managing older adults with presumed COVID-19 in the emergency department: a rational approach to rationing. J Am Geriatr Soc. 2020;68:1631-5.

10. Beauchamp T, Childress J. Principles of biomedical ethics. $7^{\text {th }}$ ed. New York: Oxford University Press; 2012.

11. Vergano M, Bertolini G, Giannini A, Gristina G, Livigni S, Mistraletti G, et al. Clinical ethics recommendations for the allocation of intensive care

\section{FUNDING SOURCES}

No funding.

treatments in exceptional, resource-limited circumstances: the Italian perspective during the COVID-19 epidemic. Crit Care. 2020;24:165.

12. Lambden $S$, Laterre $P$, Levy $M$, Francois $B$. The SOFA score development, utility and challenges of accurate assessment in clinical trials.Crit Care. 2019;23:374

13. Rockwood $\mathrm{K}$, Theou $\mathrm{O}$. Using the clinical frailty scale in allocating scarce health care resources. Can Geriatr J. 2020;23:254-9.

14. White D, Lo B. A framework for rationing ventilators and critical care beds during the COVID-19 pandemic. JAMA. 2020;323:1773-4.

15. Jeffrey $D$. Relational ethical approaches to the COVID-19 pandemic. J Med Ethics. 2020;46:495-8.

16. Coghlan N, Archard D, Sipanoun P, Hayes T, Baharlo B. COVID-19: legal implications for critical care. Anaesthesia. 2020;75:1428-31.

17. Joebges S, Biller-Andorno N. Ethics guidelines on COVID-19 triage - an emerging international consensus. Crit Care. 2020;24:201.

18. Kirkpatrick J, Hull S, Fedson S, Mullen B, Goodlin S. Scarce-resource allocation and patient triage during the COVID-19 pandemic. J Am Coll Cardiol. 2020;76:85-92.

19. A viv R, Baird R, Bilger B, Blitzer J, Cunningham V, Finnegan W, et al. Allocation of scarce critical care resources during a public health emergency executive. New Yorker. 2020;96:32-47.

20. Shalowitz $D$, Lefkowits $C$, Landrum L, von Gruenigen V, Spillman MA Principles of ethics and critical communication during the COVID-19 pandemic. Gynecol Oncol. 2020;158:526-30.

21. Pawlikowski J. The ethical dimension of prioritization and allocation decisions within the context of the coronavirus disease 2019 pandemic. Polish Arch Intern Med. 2020;130:466-72.

22. Azoulay É, Beloucif S, Guidet B, Pateron D, Vivien B, Le Dorze M Admission decisions to intensive care units in the context of the major COVID-19 outbreak: local guidance from the COVID-19 Paris-region area. Crit Care. 2020;24:293

23. Krishna L, Neo H, Chia E, Tay K, Chan N, Neo P, et al. The role of palliative medicine in icu bed allocation in COVID-19: a joint position statement of the Singapore hospice council and the chapter of palliative medicine physicians. Asian Bioeth Rev. 2020;12:205-11. 